\title{
Was it a vision or a waking dream?
}

\section{Robin Carhart-Harris* and David Nutt}

Division of Brain Sciences, Department of Medicine, Centre for Neuropsychopharmacology, Imperial College London, London, UK

${ }^{*}$ Correspondence: r.carhart-harris@imperial.ac.uk

Edited by:

Adam B. Barrett, University of Sussex, UK

Reviewed by:

Alexis Georges Hervais-Adelman, University of Geneva, Switzerland

Keywords: consciousness, REM sleep, dreaming, hallucinogens, posterior cingulate cortex, default mode network

\section{A commentary on}

Disrupting posterior cingulate connectivity disconnects consciousness from the external environment

by Herbet, G., Lafargue, G., de Champfleur, N. M., Moritz-Gasser, S., le Bars, E., Bonnetblanc, F., et al. (2014). Neuropsychologia 56C, 239-244. doi: 10.1016/j.neuropsychologia.2014.01.020

Reminiscent of Wilder Penfield's famous experiments, Neurologists in France have reported a remarkable case in which intraoperative electrical stimulations of the posterior cingulate cortex (PCC) in a conscious patient induced transient dreamlike states with vivid visual imagery (Herbet et al., 2014). The implicated circuitry and nature of the experiences evoked comparisons with findings from our own neuroimaging research with the hallucinogen and putative "oneirogen" (dream-inducer) psilocybin, strengthening what can be inferred about the importance of the PCC in mediating the quality of consciousness.

We were fascinated to read the casereport of a dreamlike experience evoked by direct electrical stimulation of the posterior cingulate cortex (PCC) in an epilepsy patient by Herbet et al. (2014). The PCC has attracted a lot of interest in recent years due to recognition of its high metabolic and vascular demand (Raichle et al., 2001) and importance as a cortical connector hub (Hagmann et al., 2008) and integration center (Leech et al., 2012). Perhaps due to its buffered location and rich vascular innervation, there is an absence of cases of focal PCC lesions (Leech and Sharp, 2014) and to our knowledge there are no reports on the effects of PCC stimulation in humans. There are a few case-reports of impaired spatial navigation and related symptoms of Balint's syndrome in patients with damage to the retrosplenial cortex (Leech and Sharp, 2014) but the stimulation site here was dorsal to the retrosplenial cortex, in white matter of the cingulum bundle, a major tract connecting the PCC with the medial prefrontal cortex (mPFC). This circuit constitutes the spine of the defaultmode network (DMN), a system that has been associated with spontaneous cognition that is suspended or interrupted during periods of externally-directed attention (Raichle et al., 2001).

Upon reading Herbet et al.'s report, we were struck by similarities between the subjective reports given post-PCC stimulation and those we observed after controlled administration of the classic hallucinogen, psilocybin (Carhart-Harris et al., 2012; Muthukumaraswamy et al., 2013). As Herbet et al. discuss, stimulation of the PCC/cingulum bundle likely inhibited activity in this region and interrupted communication between the mPFC and PCC. Importantly, altered PCC activity (i.e., decreased blood flow and oscillatory power and mPFC-PCC functional connectivity) was the most conspicuous and reliable finding of our psilocybin imaging studies and volunteers reported experiencing a dreamlike state and vivid visual imagery (Carhart-Harris et al., 2012, 2014; Muthukumaraswamy et al., 2013). Moreover, sustained improvements in well-being (Griffiths et al., 2006) and lasting decreases in depressive symptoms have been reported post-psilocybin (Grob et al., 2011) and it was remarkable to read Herbet et al.'s patient describe an absence of rumination and "absolute happiness" for a sustained period after resection of the PCC. Is it possible that psilocybin produces a sustained alteration in PCC and/or DMN activity that could account for its putative therapeutic potential (CarhartHarris et al., 2014)? This is something we intend to test in a forthcoming trial of psilocybin as a treatment for major depression (Roiser and Rees, 2012).

Finally, the theoretical implications of Herbet et al.'s report are profound. The authors note that PCC cerebral blood flow is decreased in rapid eye movement (REM) sleep relative to waking (Braun et al., 1997) and non-REM sleep (Maquet et al., 1996). It has long been a matter of intrigue to us that LSD given just before sleep onset (Muzio et al., 1966) or intravenously during sleep (Torda, 1968) markedly promotes REM sleep. The classic serotonergic hallucinogens LSD, psilocybin and dimethyltryptamine are known to produce vivid and complex imagery, especially with eyes-closed, that are often described as dreamlike (Grinspoon and Bakalar, 1979). Another common feature of the REM-sleep and hallucinogenic drug states is alterations in medial temporal lobe (MTLs) activity. For example, the MTLs are hyperactive in REM-sleep (Maquet et al., 1996; Braun et al., 1997; Miyauchi et al., 2009) and show an increased amplitude in their signal fluctuations post-psilocybin (Carhart-Harris et al., 2014) which correlates with reports of dreamlike phenomena (Figure 1). The MTLs are another area where electrical stimulation can produce vivid dreamlike visions of the sort reported by Herbet et al.'s patient (Vignal et al., 2007). MTL stimulations producing dreamlike states have been found to induce a spreading activation from the stimulation site to the temporal and visual cortex 

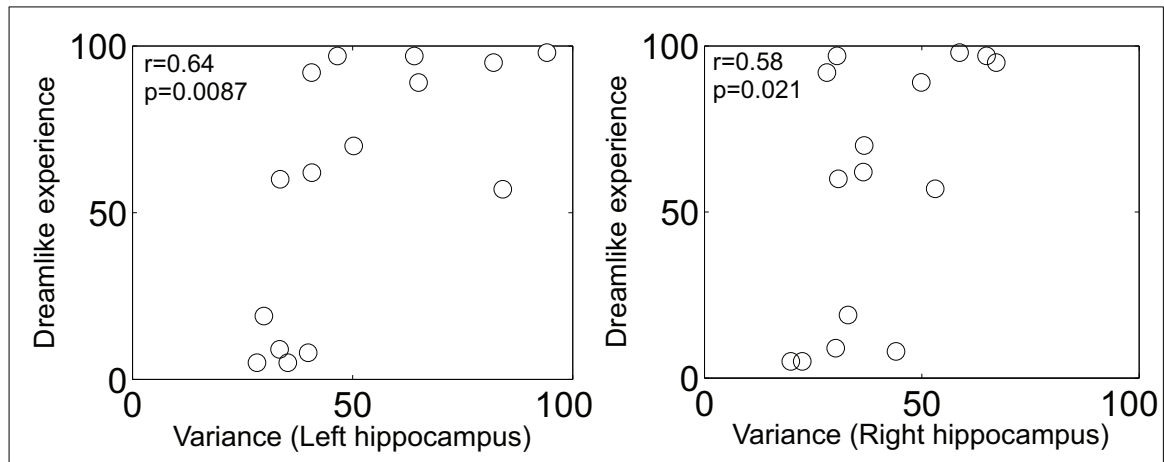

FIGURE 1 | Scatter plot of the increase in left and right hippocampal blood oxygen-level dependent signal variance/amplitude (after psilocybin infusion) vs. subjective ratings of the item: "the experience had a dreamlike quality." Both measures are expressed as a percentage increase from baseline. There were no changes in BOLD signal variance after placebo infusion ( $n=15)$ (Carhart-Harris et al., 2014).

(Barbeau et al., 2005; Bartolomei et al., 2012). However, the stimulations in the present case were in white matter and thus likely had an inhibitory rather than excitatory effect (Holtzheimer et al., 2012).

So, how might disrupting DMN activity be the cause of dreamlike visions? One way to address this question is to look for clues from studies on REM-sleep and other dreamlike states. Firstly, it is worth noting that the MTLs are major subcortical nodes of the DMN (Supekar et al., 2010) but under psilocybin, MTLDMN coupling is decreased (CarhartHarris et al., 2014). Similarly, PCC activity is decreased in REM-sleep (Maquet et al., 1996) and under psilocybin (CarhartHarris et al., 2014) but MTL activity is increased (Maquet et al., 1996; CarhartHarris et al., 2014). Since MTL activity is coupled to phasic events in REMsleep, including REMs (Bodizs et al., 2001; Karashima et al., 2007), the link between MTL activity and dreaming appears to be particularly intimate. Thus, disrupting DMN activity may have had a disinhibiting effect on MTL activity (CarhartHarris et al., 2014) and this may have been the cause of the ensuing dreamlike visions (Carhart-Harris, 2007; CarhartHarris and Friston, 2010; Carhart-Harris et al., 2014). Future neuroimaging work on dreaming and dreamlike states will help to inform these speculations.

In summary, we were struck by similarities between Herbet et al.'s findings with direct electrical stimulation of the PCC and those of our own with psilocybin and neuroimaging. Their case provides some causative support for the notion that the PCC is centrally involved in mediating the quality of consciousness (Carhart-Harris et al., 2014), and more specifically, that inhibiting the PCC/disrupting DMN activity can induce dreamlike states. Moreover, we are intrigued by the possibility that drug and stimulation-induced dreamlike states are indeed truly dreamlike, i.e., in the neurophysiological sense as well as the phenomenological.

\section{ACKNOWLEDGMENTS}

We would like to acknowledge the work of Enzo Tagliazucchi and Dante Chialvo in producing the results and plots displayed in Figure 1.

\section{REFERENCES}

Barbeau, E., Wendling, F., Regis, J., Duncan, R., Poncet, M., Chauvel, P., et al. (2005). Recollection of vivid memories after perirhinal region stimulations: synchronization in the theta range of spatially distributed brain areas. Neuropsychologia 43, 1329-1337. doi: 10.1016/j.neuropsychologia.2004.11.025

Bartolomei, F., Barbeau, E. J., Nguyen, T., McGonigal, A., Regis, J., Chauvel, P., et al. (2012). Rhinal-hippocampal interactions during deja vu. Clin. Neurophysiol. 123, 489-495. doi: 10.1016/j.clinph.2011.08.012

Bodizs, R., Kantor, S., Szabo, G., Szucs, A., Eross, L., and Halasz, P. (2001). Rhythmic hippocampal slow oscillation characterizes REM sleep in humans. Hippocampus 11, 747-753. doi: 10.1002/hipo.1090 Braun, A. R., Balkin, T. J., Wesenten, N. J., Carson, R. E., Varga, M., Baldwin, P., et al. (1997). Regional cerebral blood flow throughout the sleepwake cycle. An H2O PET study. Brain 120(Pt 7), 1173-1197. doi: 10.1093/brain/120.7.1173

Carhart-Harris, R. (2007). Waves of the unconscious: the neurophysiology of dreamlike phenomena and its implications for the psychodynamic model of the mind. Neuro-Psychoanalysis 9, 183-211. doi: 10.1080/15294145.2007.10773557

Carhart-Harris, R. L., Erritzoe, D., Williams, T., Stone, J. M., Reed, L. J., Colasanti, A., et al. (2012). Neural correlates of the psychedelic state as determined by fMRI studies with psilocybin. Proc. Natl. Acad. Sci. U.S.A. 109, 2138-2143. doi: 10.1073/pnas.1119598109

Carhart-Harris, R. L., and Friston, K. J. (2010). The default-mode, ego-functions and free-energy: a neurobiological account of Freudian ideas. Brain 133, 1265-1283. doi: 10.1093/brain/awq010

Carhart-Harris, R. L., Leech, R., Tagliazucchi, E., Hellyer, P. J., Chialvo, D. R., Feilding, A., et al. (2014). The entropic brain: a theory of conscious states informed by neuroimaging research with psychedelic drugs. Front. Hum. Neurosci. 8:20. doi: 10.3389/fnhum.2014.00020

Griffiths, R. R., Richards, W. A., McCann, U., and Jesse, R. (2006). Psilocybin can occasion mystical-type experiences having substantial and sustained personal meaning and spiritual significance. Psychopharmacology 187, 268-283. discussion: 284-292. doi: 10.1007/s00213-006-0457-5

Grinspoon, L., and Bakalar, J. B. (1979). Psychedelic Drugs Reconsidered. New York, NY: Basic Books.

Grob, C. S., Danforth, A. L., Chopra, G. S., Hagerty, M., McKay, C. R., Halberstadt, A. L., et al. (2011). Pilot study of psilocybin treatment for anxiety in patients with advanced-stage cancer. Arch. Gen. Psychiatry 68, 71-78. doi: 10.1001/archgenpsychiatry.2010.116

Hagmann, P., Cammoun, L., Gigandet, X., Meuli, R., Honey, C. J., Wedeen, V. J., et al. (2008). Mapping the structural core of human cerebral cortex. PLoS Biol. 6:e159. doi: 10.1371/journal.pbio.0060159

Herbet, G., Lafargue, G., de Champfleur, N. M., Moritz-Gasser, S., le Bars, E., Bonnetblanc, F., et al. (2014). Disrupting posterior cingulate connectivity disconnects consciousness from the external environment. Neuropsychologia 56C, 239-244. doi: 10.1016/j.neuropsychologia.2014.01.020

Holtzheimer, P. E., Kelley, M. E., Gross, R. E., Filkowski, M. M., Garlow, S. J., Barrocas, A., et al. (2012). Subcallosal cingulate deep brain stimulation for treatment-resistant unipolar and bipolar depression. Arch. Gen. Psychiatry 69, 150-158. doi: 10.1001/archgenpsychiatry. 2011.1456

Karashima, A., Katayama, N., and Nakao, M. (2007). Phase-locking of spontaneous and tone-elicited pontine waves to hippocampal theta waves during REM sleep in rats. Brain Res. 1182, 73-81. doi: 10.1016/j.brainres.2007.08.060

Leech, R., Braga, R., and Sharp, D. J. (2012). Echoes of the brain within the posterior cingulate cortex. J. Neurosci. 32, 215-222. doi 10.1523/JNEUROSCI.3689-11.2012

Leech, R., and Sharp, D. J. (2014). The role of the posterior cingulate cortex in cognition and disease. Brain 137, 12-32. doi: 10.1093/brain/awt162

Maquet, P., Peters, J., Aerts, J., Delfiore, G., Degueldre, C., Luxen, A., et al. (1996). Functional neuroanatomy of human rapid-eye-movement sleep and dreaming. Nature 383, 163-166. doi: 10.1038/383163a0

Miyauchi, S., Misaki, M., Kan, S., Fukunaga, T., and Koike, T. (2009). Human brain activity 
time-locked to rapid eye movements during REM sleep. Exp. Brain Res. 192, 657-667. doi: 10.1007/ s00221-008-1579-2

Muthukumaraswamy, S. D., Carhart-Harris, R. L., Moran, R. J., Brookes, M. J., Williams, T. M., Errtizoe, D., et al. (2013). Broadband cortical desynchronization underlies the human psychedelic state. J. Neurosci. 33, 15171-15183. doi: 10.1523/JNEUROSCI.206313.2013

Muzio, J. N., Roffwarg, H. P., and Kaufman, E. (1966). Alterations in the nocturnal sleep cycle resulting from LS D. Electroencephalogr. Clin. Neurophysiol. $21,313-324$. doi: 10.1016/0013-4694(66) 90037-X

Raichle, M. E., MacLeod, A. M., Snyder, A. Z., Powers, W. J., Gusnard, D. A., and Shulman, G. L. (2001). A default mode of brain function. Proc. Natl. Acad. Sci. U.S.A. 98, 676-682. doi: 10.1073/pnas. 98.2.676
Roiser, J. P., and Rees, G. (2012). Neuroimaging: scanner, a, colourfully. Curr. Biol. 22, R231-R233. doi: 10.1016/j.cub.2012.02.033

Supekar, K., Uddin, L. Q., Prater, K., Amin, H., Greicius, M. D., and Menon, V. (2010). Development of functional and structural connectivity within the default mode network in young children. Neuroimage 52, 290-301. doi: 10.1016/j.neuroimage.2010.04.009

Torda, C. (1968). Contribution to serotonin theory of dreaming (LSD infusion). N.Y. State J. Med. 68, 1135-1138.

Vignal, J. P., Maillard, L., McGonigal, A., and Chauvel, P. (2007). The dreamy state: hallucinations of autobiographic memory evoked by temporal lobe stimulations and seizures. Brain 130, 88-99. doi: 10.1093/brain/awl329

Conflict of Interest Statement: The authors declare that the research was conducted in the absence of any commercial or financial relationships that could be construed as a potential conflict of interest.

Received: 18 February 2014; accepted: 10 March 2014; published online: 04 April 2014.

Citation: Carhart-Harris R and Nutt D (2014) Was it a vision or a waking dream? Front. Psychol. 5:255. doi: 10.3389/fpsyg.2014.00255

This article was submitted to Consciousness Research, a section of the journal Frontiers in Psychology.

Copyright (c) 2014 Carhart-Harris and Nutt. This is an open-access article distributed under the terms of the Creative Commons Attribution License (CC BY). The use, distribution or reproduction in other forums is permitted, provided the original author(s) or licensor are credited and that the original publication in this journal is cited, in accordance with accepted academic practice. No use, distribution or reproduction is permitted which does not comply with these terms. 